\title{
Gewinn trotz tieferem Fondskurs?
}

\section{Warum dies bei regelmässigem Fondssparen möglich ist}

\section{Durchschnittspreismethode}

Vielleicht sind Sie beim Lesen von Fachzeitschriften zum Thema Geldanlagen auch schon dem Begriff «Durchschnittspreismethode» begegnet. Was oft sehr kompliziert erklärt wird, ist im Prinzip bestechend einfach: Bei der Durchschnittspreismethode werden während mehrerer Jahre regelmässig (z. B. monatlich) für einen fixen Betrag Fondsanteile gekauft, und zwar unabhängig von der jeweiligen Marktsituation. Dadurch profitieren Sie bei steigenden Preisen von Kursgewinnen. Bei sinkenden Kursen kaufen Sie mit Ihrer Einzahlung mehr Anteile, die nach Überwindung der Schwächephase überproportional an den wieder gestiegenen Preisen partizipieren.

Berechnungsbeispiel für eine jährliche Einzahlung von Fr. 6000.-

\begin{tabular}{|c|c|c|c|c|}
\hline Datum & Kurs pro Anteil & Einzahlung & Anzahl Anteile & Anlagewert \\
\hline 1.1. 2007 & Fr. 100.- & Fr. $6000 .-$ & 60,000 Anteile & Fr. $6000 .-$ \\
\hline 1.1. 2008 & Fr. 85.- & Fr. $6000 .-$ & 70,588 Anteile & Fr. 11 100.- \\
\hline 1.1. 2009 & Fr. 50.- & Fr. $\quad 6000 .-$ & 120,000 Anteile & Fr. 12529.- \\
\hline 1. 1. 2010 & Fr. 65.- & Fr. $6000 .-$ & 92,308 Anteile & Fr. 22 288.- \\
\hline 1.1. 2011 & Fr. 75.- & Fr. $\quad 6000 .-$ & 80,000 Anteile & Fr. $31717 .-$ \\
\hline 31.12. 2011 & Fr. 85.- & Fr. $30000 .-$ & 422,896 Anteile & Fr. 35 946.- \\
\hline
\end{tabular}

Obwohl der Fondskurs nach fünf Jahren $15 \%$ tiefer liegt als zu Beginn, wurde durch die Durchschnittspreismethode ein Ertrag von Fr. 5946.- erwirtschaftet, was einer durchschnittlichen Rendite von 6\% entspricht.

\section{Fondsstrategien für Ärztinnen und Ärzte}

Kennen Sie Fundlnvest, den FMH Insurance Services Fondssparplan? Durch eine clevere Kombination von kostengünstigen Indexprodukten sowie einem Anlageteil im Medizinalbereich konnte sich unser Portefeuille in den letzten Jahren von unseren Mitbewerbern abheben. Lassen Sie sich überzeugen und bestellen Sie noch heute eine persönliche Offerte.

\section{Antworttalon}

Vorname / Name

Adresse

PLZ / Ort

Geburtsdatum

Telefon Privat/Geschäft

Beste Zeit für einen Anruf

E-Mail-Adresse

Bitte senden Sie mir eine Offerte für einen Fondssparplan: monatlicher Beitrag: Fr.

Ich wünsche eine persönliche Beratung.

Bitte rufen Sie mich an.

Ich interessiere mich für:

\begin{tabular}{ll} 
O Krankenkasse & P Pensionskasse BVG \\
O Säule 3 a & O Rechtsschutzversicherung \\
O Finanz-/Steuerplanung & $\bigcirc$ Berufshaftpflichtversicherung \\
\hline
\end{tabular}

